\title{
COMPARISON OF THE COURSE SYLLABUS OF THE THEORY SUBJECT "CHEMISTRY" IN CHEMISTRY GRADE AND IN ENGINEERING STUDIES
}

\author{
J. Esteve-Romero ${ }^{1 *}$, J. Peris-Vicente ${ }^{1}$, Jaume Albiol-Chiva ${ }^{1}$, Samuel Carda- \\ Broch $^{1}$, María José Ruiz-Ángel ${ }^{2}$, Mar Esteve-Amorós ${ }^{1}$ \\ ${ }^{1}$ Department of Physical and Analytical Chemistry, ESTCE, Universitat Jaume I, Castelló \\ (SPAIN) \\ ${ }^{2}$ Department of Analytical Chemistry, Faculty of Chemistry, University of Valencia, Burjassot- \\ Valencia (SPAIN)
}

\begin{abstract}
The aim of the chemistry-related subjects, taught in the first academic year of several grades at the University Jaume I, is to provide a broad overview about general chemistry. However, these defined subjects are adapted to the structure, objectives and curricula of each grade. In this paper, a comparison of the course syllabus of the Chemistry subjects taught in the "Chemistry grade" and in several "Engineering grades" (Agricultural, Mechanical, Electrical, Industrial Technology and Chemical) is detailed. The differences and similarities of the subjects are discussed: general characteristics, justification, semester of teaching, involved teachers, departments and areas of knowledge, structure, content, competences, learning outcomes, number of credits, grouping of students, housework, numerical problems, didactic units and evaluation. The course syllabi of the subjects have been found similar, but they have been adjusted to the interests of the student, the importance of the subject within the whole curricula of the grade and the expected utility in the future career of the students. In "Chemistry grade", the content is wider and deeply explore the theoretical concepts and to strongly improve the chemistry background, which would be essential for the understanding of the following academic years. In the "Engineering grades", the content is limited to providing a basic knowledge of chemistry, focusing on the application in practical situations and the resolution of numerical problems by approaching the correct mathematical equations.
\end{abstract}

Keywords: Chemistry; Comparison; Course syllabus; Engineering; Subject.

\section{INTRODUCTION}

The EHEA philosophy states that the student must be the center of the learning process. That means the necessities and interests of the students should be primordial in the development of the educational system. Following this directive, the University Jaume I has constructed the teaching structure by emphasizing on the necessities of the students. Therefore, the curricula of the grades and the course syllabi of the subjects have been designed considering the supposed interest of the student and the expected utility for their future professional career.

All scientists must have a basic knowledge about Chemistry, whatever their specialization field. Indeed, at sometime time in their work life, they would need information about the properties of materials to solve a practical problem. Obviously, the requirement of a solid background in chemistry is not the same for all professionals, it is stronger for those focusing on the study of the characteristics and applications of materials, such as chemists and chemical Engineers. By the same way, the interests of the students are not the same. Engineers are normally interested in industrial practical applications and mathematical approaches, whereas a Chemist is more interested in the theoretical and fundamental basis of Chemistry.

The University Jaume I has included the chemistry as a compulsory subject at the first academic year of most scientific grades. In Chemistry grade, two chemistry-related subjects are taught, Chemistry I (QU905) and Chemistry II (QU9010). In the Engineering area, the subject Chemistry (EX1006) is common for Mechanical, Food and Agriculture, Electrical, Industrial Technology and Chemical Engineering grades. In all cases, the purpose of the subject is that the students get a fundamental knowledge of general chemistry. However, the curricula of the grades, as well as the necessities and preferences of the students are different. This situation should be reflected in their course syllabi. In fact, they were independently developed by the professors of each grade, without any cooperation 
between them. Besides, further modifications were performed to solve the troubles which appear through their implementation, in order to facilitate the absorption of knowledge by the students. Consequently, the didactic methodology was even more adjusted to each grade. As a result, the course syllabi of the chemistry-related subjects currently show significant differences for each grade.

The aim of this work is to describe and compare the course syllabi of the chemistry subject taught in the first academic year of the Chemistry grade in several Engineering grades (Mechanical, Food and Agriculture, Electrical, Industrial Technology). The studied aspects were: general characteristics, justification, involved teachers, departments and areas of knowledge, semester of teaching, structure, content, competences, learning outcomes, number of credits, grouping of students, housework, numerical problems, didactic units and evaluation system. The reasons for these differences have been discussed.

\section{COURSE SYLLABUS DESCRIPTION}

In Chemistry grade, general Chemistry is divided in two subjects "Chemistry I (QU0905)" (6 ECTS credits) and "Chemistry II (QU9010)" (6 credits), whereas in Engineering studies, it is taught in one subject "Chemistry for Engineering (EX1006)" (5.5 credits). The subject is the same for five Engineering grades (Mechanical, Food and Agriculture, Electrical, Industrial Technology) and the students are mixed.

The three subjects are core. QU905 and EX1006 are taught in the $1^{\text {st }}$ semester, whereas EX1006 is taught in the $2^{\text {nd }}$ semester. In QU905/QU910, all the students are in the same group, while in EX1006, they are divided in 6 groups. The three subjects include seminaries with a total duration of 0.5 ECTS credits about the resolution of practical problems. Each theory group was divided in two seminary groups. The main features of the subjects are described below:

\subsection{Justification of the subjects}

The subject QU905 aims to transmit to the students the chemical knowledge necessary for the study of the subsequent subjects. The content allows to reinforce the previously acquired knowledge and introduce other concepts that will be covered in later subjects. Some topics are simplified to facilitate understanding. The description of the atomic structure bond helps to understand the constitution of matter around us, the properties and the reactivity of chemical species. Moving in the sequence, atoms, molecules and macroscopic particles, models that explain the chemical bonding are described. These models aid to understand the behaviour of chemicals and to carry out some predictions.

The objectives of QU910 are to continue with the revision of the concepts learnt in QU905 and extend the study to other chemical principles. The nature of the solutions and the general principles of chemical reactivity are also explored. The concept of chemical equilibrium and its application to several types of chemical reactions is introduced. General concepts about thermodynamics and their application to the energetic changes of chemical reactions are discussed. The factors that govern the rate of chemical reactions and the general aspects of the chemical mechanism are explored. Finally, several notions about organic chemistry are introduced.

The purpose of EX1006 is to provide the students a basic and generalist knowledge about chemistry. Therefore, they will acquire polyvalent skills, with a wide technological overview and will be adaptable to the necessities of the industry. This would be helpful to develop their professional career, because workers with this worker profile would be very appreciated in the industrial fabrics of the Castellón area (Spain).

\subsection{Competences}

The competences expected to-be-developed by the students for the study of the three subjects are described in Table 1. 
Table 1. Competences established for the three subjects.

\begin{tabular}{|c|c|c|c|}
\hline Competences & QU905 & QU910 & EX1006 \\
\hline Autonomous learning & $\mathrm{X}$ & $\mathrm{X}$ & \\
\hline Oral and written communication in the native language & $\mathrm{X}$ & $\mathrm{X}$ & $\mathrm{X}$ \\
\hline Resolution of problems & & & $\mathrm{X}$ \\
\hline $\begin{array}{l}\text { Knowing the main types of chemical reactions and the main characteristics } \\
\text { associated with them }\end{array}$ & $\mathrm{X}$ & $\mathrm{X}$ & \\
\hline $\begin{array}{c}\text { Knowing and being able to apply the variation of characteristic properties of } \\
\text { chemical elements according to the periodic table }\end{array}$ & $x$ & & \\
\hline Knowing and applying the main aspects of the chemical terminology & $x$ & $x$ & \\
\hline $\begin{array}{l}\text { Knowing the characteristics of the different states of matter and the theories } \\
\text { used to describe them }\end{array}$ & $\mathrm{x}$ & $\mathrm{x}$ & \\
\hline $\begin{array}{l}\text { Ability to understand the main principles of general chemistry and its } \\
\text { applications in Engineering }\end{array}$ & & & $\mathrm{X}$ \\
\hline
\end{tabular}

\subsection{Learning outcomes}

The learning outcomes of QU905 and QU910 are:

1 To acquire a basic knowledge about the structure and the reactivity of the most common compounds.

2 To learn the meaning of the chemical equilibrium, the equilibrium constant and related quantitative aspects, focusing on the ionic system solutions.

3 To have a basic, but strong, background in chemistry, in order to facilitate the acquaintance of more specific knowledge in the different areas of Chemistry.

4 To become able to explain in a comprehensible form the main processes related to the basic aspects of chemistry.

5 To become able to resolve basic problems about the determination of the empirical molecular formula of the compounds. To express the composition of chemicals and mixtures in the standard units. To solve simple quantitative problems about chemical processes.

6 To acquire a basic background about thermodynamics and kinetics: the main mathematical functions regulating the behaviour of chemical reactions and their dependence on the temperature and concentration of reagents and products.

7 To clearly understand the most fundamental aspects of chemistry related to the laws of weight and the stoichiometry in the chemical reactions.

The proposed learning outcomes of EX1006 are:

1 To know the functional groups in organic chemistry and the main reactions.

2 To adjust chemical reactions.

3 To differentiate the different kinds of chemical reactions.

4 To be able to distinguish among the diverse kinds of chemical bonding and its influence over the physico-chemical properties.

5 To be able to use the chemical terminology for reagents and processes.

6 To be able of performing easy stoichiometry calculations and to determine the concentration at the chemical equilibrium.

\subsection{Content and didactic units}

The didactic units and structure of each subject are described in Table 2. 
Table 2. Comparison of the curricula of the studied subjects.

\begin{tabular}{|c|c|c|c|}
\hline $\begin{array}{c}\text { Didactic } \\
\text { unit }\end{array}$ & QU905 & QU9010 & EX1006 \\
\hline 1 & $\begin{array}{l}\text { Atomic structure and chemical } \\
\text { elements }\end{array}$ & $\begin{array}{c}\text { Types of chemical reactions and } \\
\text { solution stoichiometry }\end{array}$ & Chemical Bond \\
\hline 2 & $\begin{array}{l}\text { Chemical elements and Periodic } \\
\text { table }\end{array}$ & Chemical equilibrium principles & $\begin{array}{c}\text { Chemical reactions. Acids } \\
\text { and bases }\end{array}$ \\
\hline 3 & $\begin{array}{l}\text { Nomenclature and formulation of } \\
\text { chemical compounds }\end{array}$ & Acids and Bases I & Metallic complexes \\
\hline 4 & $\begin{array}{l}\text { Chemical bonds between the } \\
\text { elements existing in the } \\
\text { molecules }\end{array}$ & Acids and Bases II & Solubility \\
\hline 5 & Irreversible chemical reactions & $\begin{array}{c}\text { Solubility equilibria and complex } \\
\text { ion equilibria }\end{array}$ & Oxidation and reduction \\
\hline 6 & & Thermochemistry & $\begin{array}{l}\text { Introduction to organic } \\
\text { chemistry }\end{array}$ \\
\hline 7 & & $\begin{array}{c}\text { Spontaneity: Entropy and Free } \\
\text { energy }\end{array}$ & Industrial applications \\
\hline 8 & & Electrochemistry & \\
\hline 9 & & Chemical kinetics & \\
\hline 10 & & $\begin{array}{l}\text { Introduction to organic } \\
\text { chemistry }\end{array}$ & \\
\hline
\end{tabular}

\subsection{Involved professors and areas of knowledge}

The subject QU905 is taught by one professor, belonging to the Area of Inorganic of the Department of Inorganic and Organic Chemistry (QIO). The Chapters 1 to 5 of QU9010 are taught by a professor from the Area of Analytical Chemistry, belonging to the Department of Physical and Analytical Chemistry (QFA), whereas the chapters 6 to 10 are taught by a professor belonging to the Area of Physical Chemistry of the QFA. The subject EX1006 is taught by professors belonging to the four areas of knowledge in chemistry: Physical, Analytical (QFA), Inorganic and Organic (QIO). Each professor has in charge one group and lecture all the chapters.

\subsection{Evaluation}

The structure of the evaluation system is shown in Table 3.

Table 3. Relative weight of each test in the global evaluation of the subject.

\begin{tabular}{|c|c|c|c|}
\hline Test & QU905 & QU910 & EX1006 \\
\hline Participation in seminaries and tutorials & $10 \%$ & $10 \%$ & \\
\hline Oral presentations & $5 \%$ & $5 \%$ & \\
\hline Written exam & $80 \%$ & $80 \%$ & \\
\hline Resolution of numerical problems and exercises at home & $5 \%$ & $5 \%$ & \\
\hline Written report at home & & & $5 \%$ \\
\hline Partial exams & & & $15 \%$ \\
\hline Laboratory & & & $10 \%$ \\
\hline
\end{tabular}




\section{RESULTS AND DISCUSSION}

The three subjects were introduced to improve the general knowledge about chemistry, but with different specific objectives and characteristics. The differences in their course syllabi are indicated and the reasons are discussed below:

\subsection{Comparison of the justification, competences and learning outcomes}

At a first glance, we can see than the justification, defined competences and proposed learning outcomes are larger for QU905/QU910 than for EX1006. Besides, those proposed in EX1006 are superficial and point to a lower chemistry level. This clearly remarks that QU905/QU910 is an important subject in the curricula of the Grade and are addressed to students more interested in chemistry, whereas EX1006 is a secondary subject in the curriculum of the Engineering grades.

QU905 and QU9010 aim to provide them a strong background and a large expertise in chemistry, which is compulsory to understand the chemistry subjects of upper academic years. EX1006 aspires to offer a generalist knowledge about chemistry and strengthen the ability to resolve practical problem, which can extend their expertise and improve their versatility as Engineer. The justifications, the competences and the learning outcomes of the subjects clearly reflect that expected for a Chemist and an Engineer. The three subjects consider important to improve the communication skills. This is important for all the people, not only for scientists, in many aspects in our life. However, it is surprising that the "autonomous learning" has not been included as competence in EX1006, as it is an important feature for an Engineer. The "resolution of problems" should have also been included in Chemistry grade, as it is relevant for scientist from all fields.

\subsection{Comparison of the general characteristics}

The content of the three subjects deals with basic concepts of chemistry and must be included in the first academic year of their corresponding grade. The chemistry content taught in the first academic year of Engineering grades is smaller than that of the Chemistry grade, and then need a lower number of credits. For these reasons, in Chemistry grade, it is taught in two subjects, so that QU910 is the natural continuation of QU905, whereas in Engineering grades, it is taught in one subject.

EX1006 is divided in six groups, because the number of registered students is higher, as it includes students of five grades. QU905 and QU910 are addressed to students from one grade, and then one group is sufficient. The three subjects include nearly same number of credits for the theory and the seminaries about the resolution of problems. In the seminaries, the groups were divided by two to reduce the number of students and facilitate their participation.

QU905 include more fundamental concepts than QU910. In fact, QU9010 is better understood if the content of QU905 is already mastered. That is why the QU905 is taught in the first semester and QU9010 at the second one. On the other hand, the subject EX1006 is included in the first semester, as the content provides a generalist knowledge about chemistry, which should be known before dealing with other subjects

\subsection{Comparison of the general characteristics}

The didactic units (DU) of the three subjects adequately fit the justification, as well as the proposed competences and learning outcomes, of the subjects. The didactic units of QU905 and QU910 cover different topics of chemistry and their content do not overlap. The content of the didactic units of EX1006 partially coincides with that of the didactic units of QU905 and QU9010. The correspondence between the didactic units of the chemistry subjects at the Chemistry grade and Engineering grade is described in Table 4. 
Table 4. Correspondence between the content of the chemistry subjects as taught in the Chemistry grade and in Engineering grades.

\begin{tabular}{|c|c|c|}
\hline $\begin{array}{c}\text { Engineering } \\
\text { grades (EX1006) }\end{array}$ & Chemistry grade & Indications \\
\hline DU 1 & DU 1, 2, 4 (QU905) & In QU905, more detailed and focusing on theoretical aspects. \\
\hline DU 2 & DU 1; 2; 3 and 4 (QU910) & $\begin{array}{l}\text { In EX } 1006 \text {, the general concept of chemical equilibria is taught } \\
\text { quite summarized. The explanation about acid/base are nearly the } \\
\text { same }\end{array}$ \\
\hline DU 3 & DU 5 (QU9010) & \multirow{2}{*}{$\begin{array}{l}\text { In QU9010, the complex equilibria and their effect on solubility are } \\
\text { barely taught. }\end{array}$} \\
\hline DU 4 & DU 1; 5 (QU9010) & \\
\hline DU 5 & DU 1; 8 (QU910) & QU910 deeply discusses the theoretical aspects. \\
\hline DU 6 & $\begin{array}{l}\text { DU } 3 \text { (QU905) and DU } 10 \\
\text { (QU010) }\end{array}$ & $\begin{array}{l}\text { In EX1006, summarized and focusing on applications. QU910 } \\
\text { also includes the physicochemical properties of the groups }\end{array}$ \\
\hline DU 7 & $\begin{array}{c}\text { DU } 5 \text { (QU905), DU 6; } 7 \\
\text { and } 9 \text { (QU910) }\end{array}$ & These didactic units have not equivalence \\
\hline
\end{tabular}

At a first glance, we can highlight that the content of EX1006 focuses on practical aspects, a description of the industrial applications, and resolution of problems through the adequate approach and resolution of equations, whereas QU905 and QU9010 discuss the same topics and also extensively explore the associated the theoretical aspects. In fact, this coincides which that is expected about their personal interests and needing for their professional career. The following differences can be outlined:

- It is surprising that EX1006 covers in higher detail the complex equilibria. In fact, in Chemistry grade, the theoretical aspects of this topic are very important and QU910 do not have enough ECTS credits to adequately learn it. Therefore, this theme would be intensely discussed in the subject Analytical Chemistry I (QU912), taught in the second academic year. EX1006 only provides a general description about the organic nomenclature, whereas QU910 also includes the properties of these groups.

- The DU 7 EX1006 is a descriptive didactic unit about the main industrial applications, which is very interesting for Engineering. In the Chemistry grade, these applications are also described in further academic years, but together with the theoretical basis.

- The concept of irreversible reaction is missing in EX1006. It may be included, as it more fundamental than the equilibria.

- The DU 1 QU9010 provides a general introduction about the equilibria in solutions. The information is directly indicated in the DU treating each kind of solutions. A general overview about the general concept of aqueous solution is missing in EX1006.

- EX1006 does not include a DU about thermodynamics and kinetics. This should be included, as they are important aspects to control chemical industrial processes, and have a strong mathematical background.

\subsection{Involved professors and areas of knowledge}

The whole subjects QU905 and EX1006, and the DU 10 of QU9010 are taught by a professor regardless of his area of knowledge, whereas the DU $1-5$ and $6-9$ are taught by professors belonging to the corresponding area of knowledge, Analytical and Physical Chemistry, respectively. In fact, this content is more specific and is better taught by a professor skilled in these topics.

\subsection{Comparison of the evaluation system}

The evaluation system of the subjects Chemistry I and Chemistry are the same, and different to that of EX1006. The tests for the two grades are compared below:

- Only EX1006 includes a laboratory test (10\% of the final qualification), which takes 0.5 ECTS credits. In the Chemistry grade, the chemistry laboratory has its own subject (Basic Operations 
of Laboratory, QU909) with 6 ECTS credits. Because of the higher importance of the basic chemistry laboratory for Chemists, its content is more extensive and taught in more detail, so that it is better taught and evaluated as an independent subject. In Engineering, a general introduction of the chemical laboratory is sufficient and it is better evaluated as a part of EX1006.

- In the three subjects, a report at home must be performed, with a $15 \%$ weight in the total qualification. The report is made by several students, in order to improve the ability to work in groups and to stimulate the cooperation skills. In QU905/QU910, the report lies in a theoretical concept and it must be taught by the students to the rest of the class. Nevertheless, in EX1006, the topic of the report consists in the description of compound with industrial applications and it must be delivered written to the professor. This coincides with that has been above detailed as more interesting for the education of a Chemist and an Engineer.

- EX1006 includes a continuous evaluation by inserting three or four theory exams at the end of the four first didactic units. This has been proposed to stimulate the students to continually learn the content of the subject. In QU905 and QU9010, the content is too interrelated to propose partial exams.

- For QU905/QU910, the participation in seminaries and the resolution of numerical problems is evaluated, in order to incentive them to explore the resolution of practical exercises. This should also be implemented in EX1006.

- The final exam is the main test and has nearly the same weight in the three subjects. Indeed, a written exam is the best and most impartial way to qualify the knowledge of the students.

- QU905/QU910 includes a theory and practical exam, because both theory background and the ability to resolve problems are important for a Chemist. In EX1006, the exam is only practical, because the resolution of problems by means of the approach and resolution of equations is the main objective of the course. Besides, the theoretical knowledge is already evaluated by the partial exams.

\section{CONCLUSIONS}

The course syllabi of the chemistry subjects taught in the first academic year of Chemistry grade and in several Engineering grades (Agricultural, Mechanical, Electrical, Industrial Technology and Chemical) have been described and compared. The reasons of the similarities and the differences have been highlighted. The characteristics of "Chemistry I" and "Chemistry II" have been found similar, and different from those of "Chemistry for Engineering". The justification, the competences and learning outcomes clearly describe the disparity of the objectives of the two grades. The compared subjects give a global overview about general chemistry. QU905/QU910 have been structured to provide to the students a strong background chemistry (both theoretical and practical), which is compulsory to understand the chemistry subjects of the upper academic years. EX1006 has been constructed to provide a basic and generalist knowledge of chemistry, focusing on the industrial applications and the mathematical approach to resolve problems, in order to enlarge their background and improve their versatility as Engineers. In the Chemistry grade, the subjects are very important and are addressed to students strongly interested in chemistry, whereas in Engineering, it is a secondary subject. The content and didactic units have been proposed following these objectives. Therefore, we can see that the University Jaume I has considered the preferences and the utility of the subject in their future career of the students to design the subjects, as stated by the EHEA.

\section{ACKNOWLEDGEMENTS}

The article has been written with the support of the University Jaume I, by the educational project "Research about the teaching of Chemistry for Engineering".

\section{REFERENCES}

[1] Description of "Chemistry I (QU905)", Academic year 2015/2016, LLEU, University Jaume I, 2015. Available at: http://e-ujier.uji.es/pls/www/!gri_ass.lleu_asignatura_g?p_titulacion= 208\&p_asignatura=QU0905 (Accessed: 16/02/2015) 
[2] Description of "Chemistry II (QU905)", Academic year 2015/2016, LLEU, University Jaume I, 2015. Available at: http://e-ujier.uji.es/pls/www/!gri_ass.lleu_asignatura_g?p_titulacion=2 08\&p_asignatura $=$ QU0910 (Accessed: 16/02/2015)

[3] Description of "Chemistry for Engineering (EX1006)", Academic year 2015/2016, LLEU, University Jaume I, 2015. Available at: http://e-ujier.uji.es/pls/www/!gri_ass.lleu_asignatura_ $g ? p \_$titulacion=222\&p_asignatura=EM1006 (Accessed: 16/02/2015) 